\title{
The Effect of Packaging on Perceived Quality and Purchase Intention of Made-In-Ghana Brands
}

\author{
Jewel Dela Novixoxo $^{1} \quad$ Nii Adjebu Shikatse Mills ${ }^{1} \quad$ Lucy Anning $^{2 *}$ \\ 1.Department Of Marketing, Procurement and Supply Chain Management, University College of Management \\ Studies, Accra-Ghana \\ 2.School of Business Administration, Zhongnan University of Economics and Law, Wuhan 430072, China
}

\begin{abstract}
This article examines the impact of product packaging on the purchasing intention of Made-In-Ghana brands using Agbeve Herbal Centre Products as case study. Opining on the fact that packaging elements such as color, wrapper design, background image, and innovative ideas all have significant impact on consumers' purchasing intention, the study establishes that visual appeal is more significant than the qualitative aspect of packaging given the area of study. Methodologically, both primary and secondary data sources were utilized through a survey research approach. The paper argues that while many Ghanaians want to purchase made in Ghana products, the packaging discourages them. In this regard, consumers are reluctant to purchasing Agbeve herbal products due to very poor packaging. The study findings revealed that given the challenge at hand, lack of packaging design experts has hampered packaging development as there are very few packaging design experts compared to the number of SMEs in the country. Ghana, to a large extent, lacks packaging design experts to help in such areas as design, and production of packaging structures. As a result, there are many manufacturers who are ready to improve upon their packages but cannot get the necessary expertise. Also, institutions such as the Food and Drug Authority and Ghana Standard Board mandated to implement the existing but inadequate laws on labeling and packaging are faced with many challenges and hence, many products with no user information are found on the market. Furthermore, education and the influx of imported products have enlightened many consumers about what a good packaging structure is. As a result, there is a growing urge for brands to be enhanced by manufacturers which stands as a major challenge to local manufacturers, many of whom do not have the means to meet such expectations. The study therefore recommends among others that, in a bid to suiting international packaging standards, a strategic campaign on the improvement of local manufacturing climate through policy, regulatory and enlightenment framework review while complementing manufacturing of Made-In-Ghana products through exploring current packaging trends so as to enhance sales and overall trade development.
\end{abstract}

Keywords: Product Packaging; Marketing; Perceived Quality; Purchase Intention

DOI: $10.7176 /$ EJBM/11-5-09

\section{Introduction}

In an ever increasing competition of today's global market, the need for effective product promotion and marketing has become essential with product packaging playing a more important role as brand communication vehicle in this regard. Currently, virtually all products that are manufactured or processed require some packaging in some phase of their production or distribution. In effect, packaging decisions are to be considered in early marketing plans as an integral part of the total marketing strategy (Panwar, 2004). Companies usually consider several different package designs for a new product as innovative packaging bares prospects of giving a company competitive advantage in the market in which it operates. Packaging must be consistent with the product's advertising, pricing and distribution. To select the best package, companies usually test various designs to find the one that stands up best under normal use, easiest for dealers to handle and receives the most favorable consumer's response (Lu et al., 2007). Several researchers explored the potential elements of packaging and their effect on consumer's purchasing intention (See for instance, Butkeviciene, Stravinskiene and Rutelione, 2008), however others focus on distinct elements of packaging and their influence on consumer purchasing intentions (See, Ampuero and Vila, 2006; Madden, Hewett and Roth, 2000; Underwood, Klein, and Burke, 2001; Bloch, 1995). Made-in-Ghana products are easily identified if one compares its features with foreign products due to its poor packaging features. The low patronage of made-in-Ghana products can be attributed to the lack of effective packaging of the products. If made-in-Ghana products were to compete effectively in the market, packaging and its attractiveness has to be critically improved. Previous researchers indicate that there is no agreement on overall classification of packaging material and package elements. To this effect, this paper therefore sought to examine the extent to which packaging influences the purchasing intention of customers and ways to enhance and improve the sales among Made-In-Ghana products with special emphasis on Agbeve Herbal products. In terms of organization, the paper will present a background and context of the packaging of Ghanaian products with emphasis of Agbeve Herbal products, the case under study. A review of literature on the overview of packaging in the context of national and international will then be presented, followed by the research method of the study. The findings of the data on packaging of Agbeve Herbal products in relation to the purchasing decision of 
customers will be discussed, before outlining the conclusion and recommendations of the study in the form of policy review and strategies.

\section{Literature Review}

\subsection{Packaging: Historical Overview}

As opposed to the current packaging trends, the main focus in packaging used to be on the covering and protection aspects of the product. The products were placed in reliable, common materials usually from natural resources such as wood pulp (paper, cardboard) or textiles (flour sacks) that enabled consumers to enjoy the contents of package at home. For many, the most common material used to protect products were paper and glass. People understood the role of packaging as meant to protect their product on the way home from market. The manufacturing technology changed the whole concept of packaging after the Industrial Revolution in eighteenth century when manufacturers were forced to develop more resilient types of protection so the products could be transported from factory to shop and later to customer's home. Unfortunately, even 200 years ago, companies did not have enough information and research information to discover techniques that would expand the shelf life of products (Barboza, 2013).

Plastic and other compounds were not used then, so manufacturers had rather low variety of materials to choose from. It is commonly acknowledged that the development of the plastic materials for manufacturing began in the 1860s (Robertson, 1965 retrieved in 2013) by altering hard rubber. Later, synthetic plastics were gradually invented, starting with Celluloid. Nobel Prize winner Hermann Staudinger dedicated his career to study polymer science. He invented multiple compounds amongst which was polyvinyl chloride (PVC) used in vast quantities in modern packaging. In the middle of 1940s, further study of synthetic polymers by DuPont chemists synthesized polyethylene terephthalate (known as PET) used for manufacturing of plastic bottles until this day (Kruparova, P. (2007). In the twentieth century, American brewers became used to things manufactured from tinplate and steel coated with chromium which were previously used in Europe during war, to sell their beverages inside protected atmosphere (Coles and Kirwan, 2011) but this invention was also attractive for companies producing soup or preserved fruits (Robertson, 2013). As mentioned in a book written by Anne and Henry Emblem, describing fundamentals of packaging, the first easy open beverage can was invented in 1962 by American Ermal Fraze. Packaging is a central marketing tool for health products and is, in the judgment of marketing experts and courts, a form of advertising (World Health Organization, 2009). Pharmaceutical companies monitor and alter packaging on a regular basis to ensure its continuous and increasing appeal to target audiences (McDonough, R. P. (2013).

\subsection{The Global Packaging Industry}

If there is an industry sector that is equally, if not more dynamic than the food sector, it is none other than the packaging industry. It is undergoing transformation almost every day with new technologies, better than before, taking the place of old ones (Dauvergne, P., \& Lister, J. (2012). Consumer behavior, product demand and the current level of global warming are all going to have a direct impact on the future of packaging, the report stated.

\subsubsection{Packaging Industry composition}

The packaging industry is composed of two major components, namely, the supply side or providers of packaging products and the demand side or end users (Figure 1). Each component's category is characterized by varying investment status and potentials, contingent upon growth stimuli in each sector.

\subsubsection{Supply Side - By Nature of End Product}

As for the type of end product, packaging manufacturing has globally the greatest share of the total industry (81\%), followed by the packaging service (14\%) then by packaging machinery $(5 \%)$. Packaging machinery is equipment for uses such as canning; container cleaning, filling, and forming; bagging, packing, unpacking, bottling, sealing and placing of lid; inspection and check weighing; wrapping, shrink film and heat sealing; case forming, labeling and encoding; palletizing and de-palletizing, and related uses (US Dept. of Commerce, 2009). The packaging machinery sub-sector is highly globalized, with European countries and the USA dominating the top ten lists of major country producers and exporters. The world production of packaging machinery reached $€ 22$ billion in 2007 (Hebert, R. C. et al. 2010). 
Figure 2. 1: The packaging industry

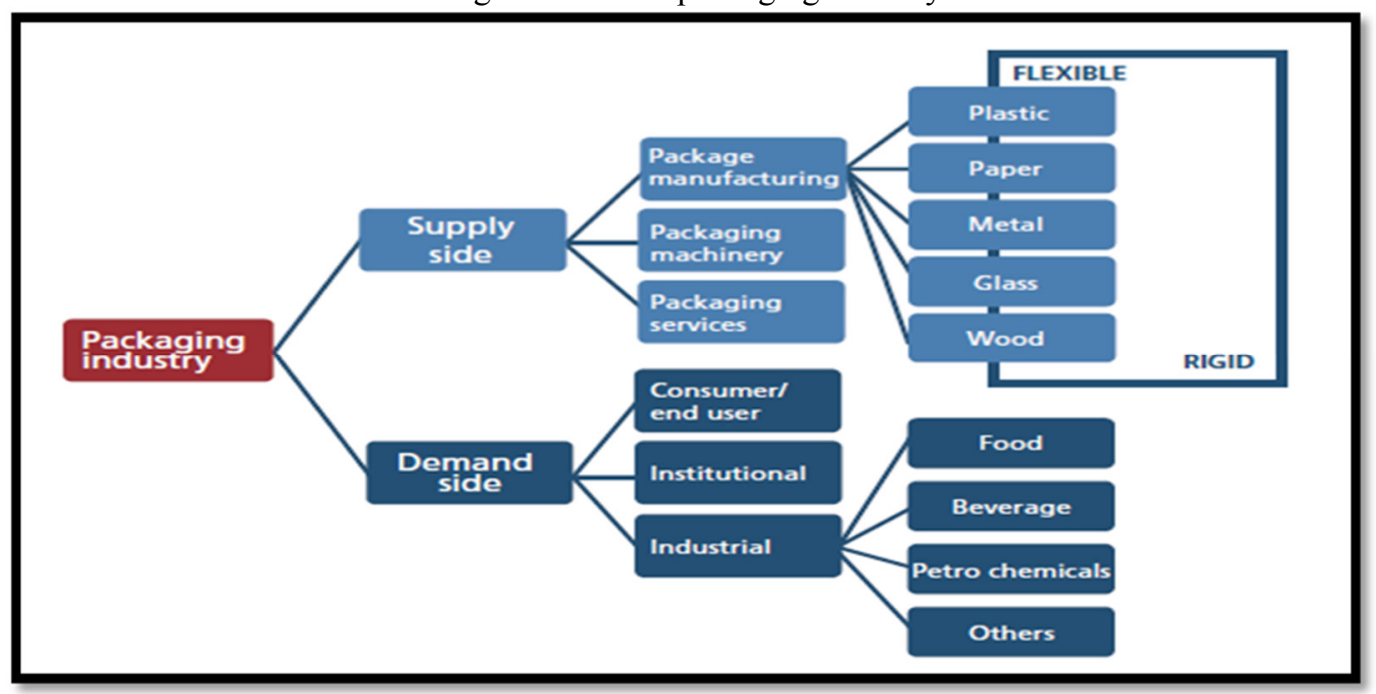

Source: Packaging Gateway (2010)

Packaging refers to the technology and material for enclosing or protecting products for distribution, storage, sale, and use (Soroka, 2002). The packaging manufacturing sub-sector is not so much globalized, with exports ranging only to a quarter of the total market volume. This is attributed to its general tendency to set up operations nearer to its end market to cut down on variable costs. The sub-sector is likewise comprised largely of small and medium enterprises (SMEs) with a greater number falling under the less than 10 employees' classification, particularly for the wooden packaging manufacturing. The packaging service sub-sector is comprised of establishments primarily engaged in the packaging and labeling of client-owned materials (such as food products) usually undertaken on a contract or outsource basis. It is important to note that this sub-sector does not include manufacturing of the packaging or the label itself.

\subsubsection{Supply Side - By Form and Type of Packaging Material}

As for form, packaging can either be flexible or rigid with the former fast replacing the more traditional rigid form, owing to cost and flexibility advantage. Flexible packaging includes materials such as film, foil or paper sheeting. Rigid packaging includes glass, rigid metal, and wood. As to the share of the total packaging market, paper (34\%) tops the list, followed by rigid plastic (27\%), metal (15\%), glass $(11 \%)$, flexible packaging (10\%), and others (3\%). The flexible packaging market is expected to grow by around $3.2 \%$ annually over the next five years with food accounting for $75-80 \%$ of the demand. To retain its current share of the market, rigid packaging has to address the cost advantage of its flexible counterpart, while affording flexibility and variety of uses.

\subsubsection{Demand Side - By End User Product or Industry}

On the demand side, the packaging industry may be classified in relation to the type of end user, namely: individual consumers, institutional and industrial users with the latter further sub categorized by industry type, namely, food, beverage and petrochemicals. Food accounts for $50 \%$ of the global consumer packaging industry valued at US\$ 380 billion as of 2009. If the beverage sector is to be added, that will even increase to $69 \%$ (Figure 2). That the food and beverage market accounts for more than half of the packaging market are a worldwide phenomenon. In developing countries, the growing demand from the food and beverage market has been instrumental in stimulating the overall growth in the packaging industry (Global Industry Analysts, 2010).

Figure 2.2: The global consumer packaging industry, by end use, 2009

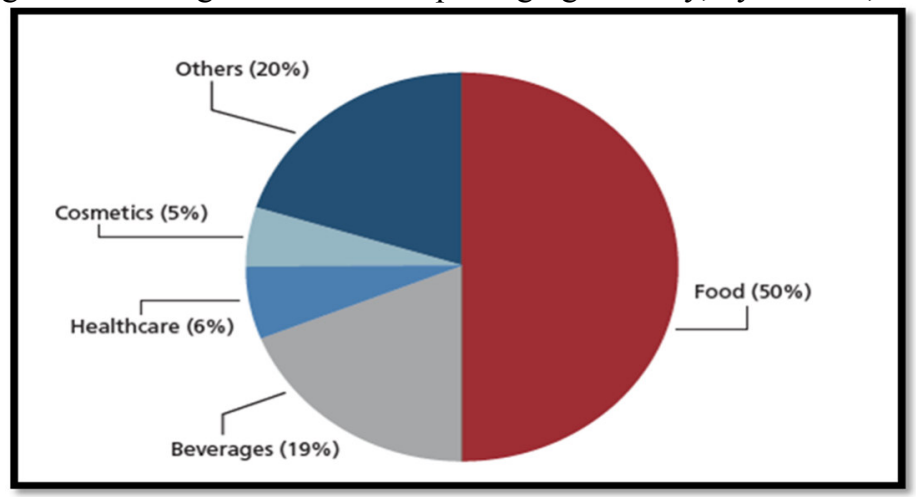

Source: PIRA International, 2009 


\subsection{Functions of Packaging}

Every package has several basic functions that are described by authors and textbooks in various forms, although they contain similar structure. Fundamentally these functions are containment, protection, preservation, convenience and information. The list of additional functions mentioned by publications and organizations include: communication, selling, presentation, promotion, environmental responsibility and other. If a package is designed to fulfill its function, it must endure all basic functions in three environments: ambient, human and physical (Robertson, 2013). When designing and manufacturing, these functions are taken into consideration by companies and the output is the specific package found on shelves of retailers. Packaging functions are all considered necessary for each product even though some are being more endorsed by certain manufacturers. It often occurs that a package lacks in one or more of the functions categories (Faus, N. L., \& Pierce, D. L. (2016).

When producing goods, the main focus often shifts from the end consumer. The fact that packaging is supposed to fulfil the requirements of customers may conflict with business objectives set by producers as for example costs, availability, brand image, marketing and therefore the objectives of society are considered secondary. One of the functions that is rarely mentioned in books when reading sections about functions of packaging is sustainability. Especially in current state of the environment, this function should be on the top of manufacturer's priorities in order to create less waste and enable consumers to recycle or reuse the package after they consume or unboxed their product.

\subsection{The Influence of Product Information (Labeling) On Consumers Purchasing Intention}

'For a message to have an effect it must be believed' (Sevilla, 2012). On any package, information will either be displayed on the package directly or included on the label. Such information ranges from the name of the product to the product composition list, manufacture and expiration dates, location of manufacture etc. It is crucial in the current time that information about a product is present on the package, and as such to serve the dual role of communicating product benefits and detriments in equal measure. America has viewed this with vigor and package information must disclose even warning signs so that the consumer is fully aware of the product attributes (Risgalla, E. (2006).

It has also been held that the closer the proximity of the message is to the consumer, the more believable it is since advertisements and other promotional tools have been shown to have sense of distance between the consumer and the product. This not only applies within the sphere of marketing but acts as a basic psychological principle of proximity and message acceptability. This theory holds that the level of human acceptability of any information is increased once the communication medium is brought to a closer range. This therefore informs marketers on the information content to place on a product's package as it draws a consumer closer to the product as compared to other forms of promotion like advertising (Sevilla, J., 2012).

Logos have also been incorporated in labels, and corporate manufactures with strong logos and trademarks in the cosmetic industry use these to elbow past competition as they capitalize on consumer familiarity with their brands. Information on the label is thus vital in pushing a product in the market especially when used by renowned brands such as Calvin Klein, Gucci, Dior and Prada (Suppakul, P. et al. (2011).

One approach when it comes to labeling is the basic functionality behind it such that a label should essentially have two parts; the front label that evokes consumer interest and bears the marketing function of attractiveness, and the back label that has the technical informational content of the product. The relationship between these two labels should essentially be harmonious, as in the Gestalt Law of Figure and Ground, as the consumer will not assess the two independently, but the back as a continuation of the front. That said, emphasis is further placed on the shape, size and position of the label as well as the nature of the inscription on it. Whether the information on the label tells a story of the product or simply has a catchy ring to it is vital in determining the level of consumer interest in the product. However, the foundation of it all is to ensure that the information displayed on the package or label is true and relevant, so that the consumer feels a sense of trustworthiness in the overall presentation of the product (Rocchi and Stefani, 2006; Seville, 2012).

The matter on communication of value that is vested on a label is worth looking into. A consumer responds positively to information that is well written and clear, since if the label looks well organized, then the consumer perceives higher care given to this particular product hence greater perceived quality. Another aspect mention in this study that looked into the perception of consumers on the value of wine packaging was the presence of a watermark on the label. There was an intrinsic feeling of exclusivity or that the item is rare and almost collectable. It all boils down to the content of the information and how it is presented (Rocchi and Stefani, 2006). The information selected to appear on a package should be done carefully, to ensure that a positive lingers in a consumer's mind repeatedly. This repetitive nature is primarily for the purpose of product recollection, ensuring that the desired image is retained in the consumer's mind constantly to evoke product choice. The underlying principles behind this are the Gestalt Laws of Closure and Continuation; stating the ability of the mind to complete and incomplete form and mentally perceive it as a whole, and the ability to gradually progress from one form to the next, respectively (Spokane Falls Community College, 2013). Closure and continuation work hand in hand 
when it comes to information; giving the consumer a basis on which to build an image and generate expectations, preferably that the product is superior to the rest on the shelf (Konnikova, 2014). An important factor to note as this study is undertaken would be to understand the extent to which information (label) attracts consumer interest and stimulates choice.

\subsection{Marketing of Pharmaceutical/Medical Products}

Advertising is suited to the transmission of simple, focused messages. When consumers require detailed information about certain health products, they pursue many sources, such as package inserts, websites, etc., to inform their product decisions. Comparatively, advertising ranks low as a source of information by which consumers make decisions. Product labels and advice from healthcare professionals continue to be the most highly valued sources of information. However, advertising does have a role to play by providing consumers with the awareness needed to begin the search for an appropriate product when the need arises. The key role of television advertising is to establish awareness of product choices and to articulate the key benefit to a mass audience. To be effective, this advertising must be simple and consumer friendly (Blinn, 1989).

Considerable controversy surrounds the practice of direct-to-consumer (DTC) marketing of pharmaceuticals. While some argue that DTC advertising serves as an educational resource for patients (Holmer, 2012), others say that DTC advertising contributes to the medicalization of trivial ailments, and leads to overuse and misuse of pharmaceuticals (Ilić, Z. S. et al. (2012). Dieringer et al., (2011) did a study on self-reported responsiveness to direct to consumer advertisement and medical use using data from U S. he used data from national telephone survey of adults in the US investigating the demographic and attitudinal effects of direct-to consumer advertising of survey respondents. The study employed statistical tool such as chi-square and t-tests. They found that there is no relationship between the number of OTC medication taken and the propensity to discuss health related problem in response to direct-to-consumer advertisement. There is strong linear relationship between self-medication, demographic and socio-economic factors.

A study conducted by Donohue and Berdt (2004) on the effects of direct-to-consumer advertisement on medication choice. The study used structured questionnaire and multinomial logistic model as well as descriptive statistics. The study found that direct-to-consumer advertisement for antipressant has little effects on drug choice. The study examined whether the effects of pharmaceutical promotion varied by individual characteristics, in response to changes in the regulatory environment, and over the course of a product's life cycle. Whereas DTCA spending did not appear to influence drug choice for people with major depression, it had a positive and statistically significant effect on medication choice for people who were diagnosed with anxiety disorders.

A study conducted by Joan Buckley (undated) on proper pharmaceutical marketing - time for change found that there is negative impact on self-medication as a result of misleading advertising, disease mongering and escalating cost on medical care. Andualem (2002) did study on people knowledge in self-medication and their perspective in Addis Ababa, Ethiopia and found that the most common reasons for self-diagnosis and selfmedication were non-seriousness of the diseases and prior experience about the drugs. While much has been written regarding consumer and physician attitudes toward DTC advertising, less is known relating Patient characteristics, notably medication use, and responsiveness to DTC advertising (Dieringer, 2011). One survey found that respondent's attitude towards DTC advertising were more likely to be nonwhite, have lower educational attainment and lower income, (Robin et al., 2004) whereas Bell found that women, as well as persons with a positive attitude towards DTC advertising, in poorer self-reported health, and with better self-reported insurance coverage of medications were more likely to respond to DTC advertising (Okano, M., 1999).

A study done by Moran and Kosali (2006) on income and the use of prescription drugs by elderly using evidence from notch cohorts in US. The study used exogenous variation in Social Security payments created by the Social Security benefits notch to estimate how retirees' use of prescription medications responds to changes in their incomes. In contrast to estimates obtained using ordinary least squares, instrumental variables estimates based on the notch suggest that lower-income retirees exhibit considerable income sensitivity in their use of prescription drugs. It found small and statistically insignificant effects of income on the number of prescriptions used by each household when these effects are estimated by ordinary least squares. By contrast, when the benefits notch is used as an instrument for household Social Security income, they found large and statistically significant effects of income on drug use across all three model specifications, with the magnitude of the income effect rising a bit as tighter controls for age are incorporated. Focusing on the quadratic age specification, our coefficient estimate indicates that a \$1000 increase in Social Security income (in 1993 dollars) would increase the number of prescription medications used in a typical month by approximately 0.55 per household. Evaluated at the mean levels of drug utilization and Social Security income in the sample translates into an elasticity of approximately 1.32, implying a high degree of income sensitivity on the part of lower-income retirees (Moran and Kosali, 2006).

A study compiled by Michele and Dold (2013) on the role of "African chemists" in health care system in the Eastern Cape province of South Africa. The study employed standardized questionnaire on the target group at the various drugs outlet in the province. The study uses descriptive system of analysis and it found that they were 
more female (54\%) consumers than male (47\%). Those who seek healthcare from African chemist had low level of education. The study also found that self-medication was major factor in curing sickness at initial stage and African chemist play part.

Nonvigon et al. (2010) did a study on the treatment choices in children under-five in a rural Ghana districts. They used data from 2006 household socio-economic and health and demographic surveillances covering caregivers 579 children under- five years of age in the Ga-Dangme west district and applied multinomial probate model to model the choice of treatment for fever under-five years in rural Ghana. The findings indicate that longer waiting time and treatment time encourage people to use self-medication and over the counter treatment compared to public and private owners. Also, they found that caregiver with health insurance uses public care and those caregivers with male under-five uses public health services whiles caregivers with female under-five uses selfcare.

An empirical study by Assenso-Okyere et al. (1998) on the impact of health care seeking behavior of the costs sharing policies introduced in Ghana between 1985 and 1992 in some selected districts in Ashanti using qualitative data analysis and found that cost recoveries policies have led to the increase in self-medication. They also found that there is an increase drug supply situation in the country with cost recovery policies.

\section{Research Methods}

In line with Novixoxo et al. (2018a, 2018b) and Darko, S., (2018), the study adopts a descriptive research design in analyzing the phenomenon. Data were collected through questionnaire and interview techniques. The working population for the study is 900 consisting of staff and customers of Agbeve Herbal Centre in the Greater Accra Region of Ghana. Yamane's (1967) technique on sample size determination was used to get a sample of 277. Of these sample, 270 copies were retrieved with $90 \%$ success rate. The descriptive design involves evaluating how different factors are perceived by the consumers and how they affect their behavior and choice. Since the study is aimed at analyzing the influence of product packaging on consumer purchase intention of Agbeve herbal products and brand, it was appropriate to undertake a descriptive design to give more insight on consumer purchase behavior and statistically shed light on justifications of whether pharmaceutical manufacturers should increase the expenditure on packaging technology, based on the outcome of this study (Neuman, 2007). According to Osuala (2001), descriptive surveys or quantitative research methods are versatile and practical, especially to the researcher in that they identify present conditions and point to the present needs. Gay (1992) also expounds that descriptive research is one which specifies the nature of a given phenomenon. It determines and reports the way things are (Kavulya, 2004; Creswell, 2008; Vasileiou and Rowley, 2011). The researchers find this technique appropriate to use because the sample was taken out of a diverse population of Agbeve Herbal Centre in their natural environment and a questionnaire was administered to seek participants' answers to questions.

\section{Data Analysis, Results and Discussion}

This section focusses on the actual research findings and discusses data on the perceptions of packaging given data obtained from the field survey from the staff and customers of a Made-in-Ghana product brand thus Agbeve herbal products. The data are organized and discussed under each sector heading. In this study, one hundred (277) questionnaires were administered to the respondents both customers and staff alike. However, all the questionnaires were not completed successfully by the respondents and returned to the researcher. Hence, two hundred and seventy (270) valid questionnaires were ultimately received and used in the analysis which consist of sixty-nine (69) from the staff and two hundred and one (201) from the customers.

Table 4.1: Years Worked/being a customer with Agbeve herbal Centre

\begin{tabular}{|l|l|l|l|}
\hline Detail & Customers & Staff & Total/Percent \\
\hline 1-5 Years & 77 & 18 & $95(35.18 \%)$ \\
\hline 6-10 Years & 51 & 20 & $71(26.29 \%)$ \\
\hline 11-15 Years & 31 & 12 & $43(15.92 \%)$ \\
\hline 16-20 Years & 26 & 9 & $35(12.96 \%)$ \\
\hline 21 Years+ & 16 & 10 & $26(9.62 \%)$ \\
\hline Total & 201 & 69 & $270(100 \%)$ \\
\hline
\end{tabular}

Source: Field Data (2018).

Aside the basic biographic data of the age of the respondents, the table above show the number of years customers and staff alike have worked with Agbeve herbal Centre. All respondents were duly interviewed so as to have general information espoused from them to achieve the set objectives of the study. The years worked with AHC variable indicated that, both customers and staff selected for the study have had enough working years with the Centre. This will go a long way to help in the analysis, since majority of the respondents both side of the staff and the customers will give the exact customer relationship experiencing from the staff and rendering to the customers. 
Figure 4: Highest Level of Education of Staff

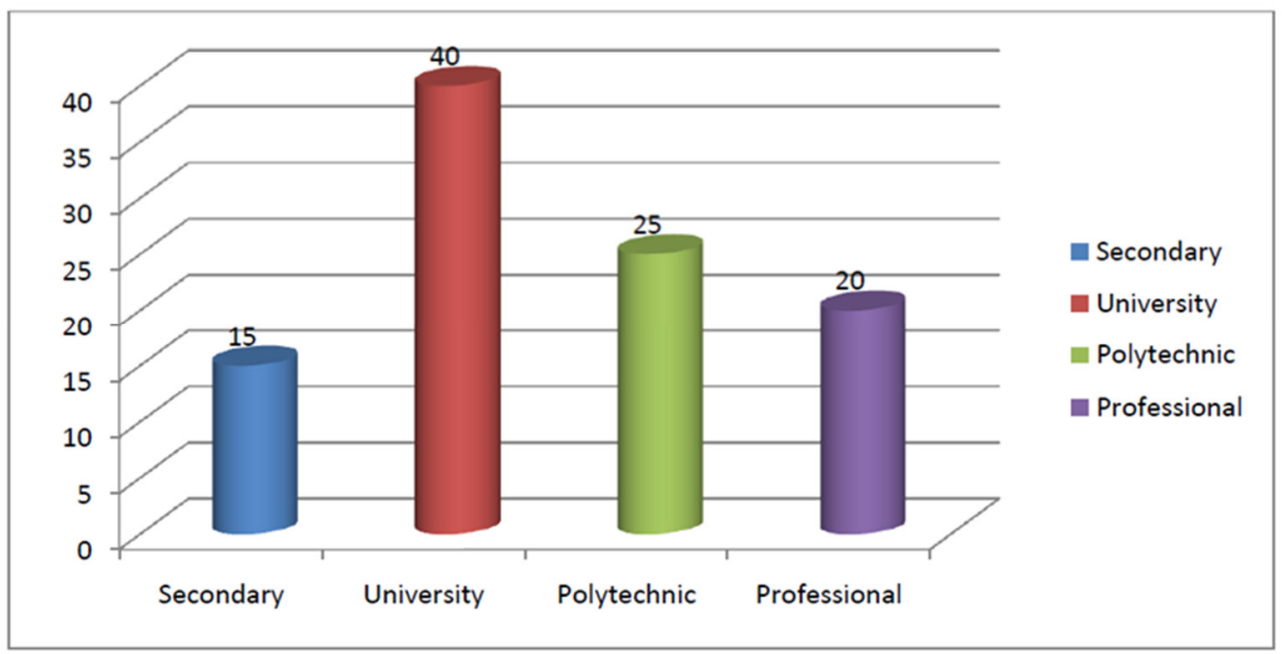

Source: Field Data (2018).

Educational level of staff of the Agbeve herbal Centre further depict that, majority were university graduates followed by polytechnics, professional and secondary school graduates, representing 40\%, 25\%, 20\% and $15 \%$ respectively. Figure 4.1 shows that, the Agbeve herbal Centre have enough staff holding the required relevant qualifications needed to effectively deal with customers.

A person's level of education reflects the approach employed in handling a task and also how innovative they are toward work thus overall efficiency in being productive on the job. In this study, the educational level was considered highly essential to adequately assess the enlightenment levels of the respondents. Also, there is a direct relationship between the level of education and the ability of people to demand the right services and products for money paid (value for money). Sometimes, they are called 'book-long". Figure 4 above shows the distribution of the educational levels of the sampled respondents of staff and customers within the greater Accra region of Ghana.

\subsection{Response from Customers: Perceived Intentions of Agbeve Herbal Products}

The consumers or customer's data gathered and presented includes the demographic and social characteristics, factors that account for rejection of Agbeve herbal Centre products and their various behaviors amidst the comparison of packaging of Made-in-Ghana products in relation to foreign products. This section presents analysis, results and discussions on the condition and nature of packaging of Made-in-Ghana products from Agbeve herbal Centre products and also gives account on the reasons for the low patronage of Made-In-Ghana products from Agbeve herbal Centre products.

\subsubsection{Purchasing Centers}

Location is an essential factor in obtaining wholesome and better Made-In-Ghana products and hence the study sorts to assess the common locations where sampled consumers purchased their Agbeve herbal Centre products. From the survey, it was established that majority of respondents (about $45.5 \%$ representing 103 respondents out of a total of 201) did their shopping from "anywhere convenient" (refer to Table 4.1). This is very relative because everybody can have criteria for determining a place which is convenient to buy a product however, the opinion of the consumer is paramount. It was also dependent on the type of product one needed to buy. This was followed by consumers who largely purchase products from the local markets such as the neighborhood /satellite markets or the main central market at Kaneshie and circle constituting about 22.8\% as can be observed from Table 4.1.1. Given the fact that the most common products sold here are fruits and vegetables which is relatively varied from Agbeve herbal Centre products, this group of respondents argued that they did not know the source and ultimately, the guaranteed safety of the products. Also, sometimes the hygienic conditions of the traders and their location left much to be desired. Those from shopping malls such as the big shops in town namely West Hill Hall, the Goil/Shell/Mobile Marts, etc constituted about 18.9\% constituting of 38 respondents (See Table 4.1.1). Some consumers held the perception that buying Agbeve herbal Centre products from shops and supermarkets are for the elite. The respondents who patronized the shopping malls, however, were of the view that the shopping malls sold wholesome products and because they took stock on a daily basis, never sold expired products. 
Table 4.1.1: Purchasing Centers

\begin{tabular}{|l|l|l|}
\hline PURCHASING CENTER & FREQUENCY & PERCENTAGE\% \\
\hline Shopping Malls & 38 & 18.9 \\
\hline Local Market & 46 & 22.8 \\
\hline Street Traders & 14 & 6.9 \\
\hline Anywhere Convenient & 103 & 51.4 \\
\hline Total & 201 & 100 \\
\hline
\end{tabular}

Source: Field Data (2018).

4.1.2: Factors Considered by Consumers before Buying Agbeve herbal Centre products

The decision or consumers purchasing intention require certain factors that needs to be considered. This is proportionate to the choice and selection of a product. Whereas others consider the need and desire for consumption, others consider the satisfaction of beauty in which the product is made of and not necessarily the need. For the purpose of this study, the need to understand and appreciate the factors that consumer's lookout for when making a decision to purchase Agbeve herbal Centre products cannot be overemphasized. This is because packaging designers need such knowledge to understand what consumers expect to see on the packaging. Manufacturers also, need to appreciate these factors so that they can demand from the designers the right packaging to make the right sales and profits. Consumers who are the final users of all products would also be well equipped so that they make the right choices. Many customers admitted to setting their purchasing intentions basing on the color and attractiveness of the packaging of the products. Table 4.1.2 elaborates on the different opining views from respondents.

Table 4.1.2: Factors Considered by Consumers before Buying Agbeve herbal Centre products

\begin{tabular}{|l|l|l|}
\hline Items & FREQUENCY & PERCENTAGE\% \\
\hline Beautifully Packaged & 70 & 34.9 \\
\hline Need for the product & 81 & 40.4 \\
\hline Packaging providing the needed information & 20 & 9.9 \\
\hline Manufacturing and Expiry Dates on product & 22 & 10.9 \\
\hline Contents of the Product & 8 & 3.9 \\
\hline Total & 201 & 100 \\
\hline
\end{tabular}

Source: Field Data (2018).

From the Table 4.1.2 above, the most critical factor considered by consumers in the choice and selection of Agbeve herbal Centre products is the need for that particular product. The necessity for the product is the major priority issue considered by most consumers before affirming their purchasing intentions. This variable accounts to $40.4 \%$ constituting 81 of the distribution. Also, a section of the consumers considers the beautiful and attractive nature of the package as a key factor to purchasing a product. This view shared by this group of consumers is in conformity with this research work. This view was expressed by 70 respondents constituting $34.9 \%$ of the overall distribution. The number of respondent who consider the expiry date of the product prior to setting their purchasing intention amounted to $10.9 \%$ constituting 22 of the sample under study. Packaging providing the needed information and content of the product consisted of 20 (9.9) and 8 (3.9) respectively

\subsection{Influence of packaging on purchasing decision of Agbeve herbal Centre products}

A further investigation was undertaken to ascertain whether consumers really consider packaging as a determinant in their purchasing decision of Agbeve herbal Centre products and the graph below indicates the response of the consumers. Indeed, table 4.2 confirm the strong influence packaging has on the purchasing decision of consumers. Out of the overall respondents, 131 constituting $65.1 \%$ confirmed that they are influenced by the packaging while the remaining 70 of the respondents constituting $34.8 \%$ expressed that they were not influenced by the packaging of the product. The table 4.2 .1 below shows this details.

Table 4.2.1: Influence of packaging on purchasing decision

\begin{tabular}{|l|l|l|}
\hline ITEM & FREQUENCY & PERCENTAGE\% \\
\hline YES & 131 & 65.1 \\
\hline NO & 70 & 34.8 \\
\hline TOTAL & 201 & 100 \\
\hline
\end{tabular}

Source: Field Data (2018).

Respondents also indicated various reasons why the packaging of Agbeve Herbal products will influence their purchasing intentions. This is shown in table 4.2.2 below. 
Table 4.2.2: Reasons why Packaging Influences Purchasing Decision

\begin{tabular}{|l|l|l|}
\hline RESPONSES & FREQUENCY & PERCENTAGE\% \\
\hline Good packaging do attract me to buy a product & 85 & 42.3 \\
\hline Package gives good impression of the product quality & 36 & 17.9 \\
\hline Package determines the quality of the product & 22 & 10.9 \\
\hline Nice colors mostly influence my decision & 17 & 8.5 \\
\hline Package Provides all necessary information & 11 & 5.4 \\
\hline Product's beauty attracts my attention to buy & 30 & 14.9 \\
\hline Total & 201 & 100 \\
\hline
\end{tabular}

Source: Field Data (2018).

Following the responses provided by the respondents on whether they are influenced by packaging in their purchasing intention, the study sought to find out the reasons why packaging influences their purchasing decision of Agbeve herbal Centre products. This was aimed at validating the issues raised from the problem statement and the literature review and investigating the depth and spread of these factors as well as unearthing whatever new and unknown factors that existed and which had some influence no matter the extent. Table 4.4 presents the results of this analysis. The data revealed that most consumers were enticed to impulse buying of certain products which hitherto are not planned for as a result of the attractive nature of the package. This reason is shared by majority of the overall respondents constituting $42.3 \%$. Respondents also affirmed that the nature of packaging to a larger extent determines the quality of product hence they are forced to buy. It accounts for $14.9 \%$ from the views of 30 respondents (See Table 4.2). Other opinions shared included the presentation of good impression about the product quality and the provision of all necessary information. This constitute $17.9 \%$ and $5.4 \%$ respectively (See Table 4.2). The above analysis confirms the assertion made by Judd, Aalders and Melis (1989) that, packaging is the silent sales man and that with $75 \%$ of the purchasing decisions are made at the shop, all attention need to be directed at making the products very attractive in terms of colour, shape, size etc. while providing all the needed information such as manufacturing and expiry dates, instructions for usage, care and storage instructions.

\subsection{Purchasing of Made-In-Ghana Products}

In pursuit of achieving the objective of this research, it was highly imperative to know the number of respondents who purchase Made-in-Ghana products from Agbeve herbal Centre and those who do not and understand the reasons behind their actions and inactions. Table 4.3.1 portrays a high dominance of patronage of Made-in-Ghana products by Agbeve herbal Centre products given the sampled consumers. Majority of the entire respondents thus $(65.6 \%)$ confirmed their patronage of these products. However, most of them would purchase the locally manufactured products out of convenience or due to their inability to purchase the imported ones given their high prices $(34.3 \%)$.

Table 4.3.1: Purchasing of Made-In-Ghana Products

\begin{tabular}{|l|l|l|}
\hline ITEM & FREQUENCY & PERCENTAGE\% \\
\hline YES & 132 & 65.6 \\
\hline NO & 69 & 34.3 \\
\hline TOTAL & $\mathbf{2 0 1}$ & $\mathbf{1 0 0}$ \\
\hline
\end{tabular}

Source: Field Data (2018).

Furthermore, consumers of locally manufactured products such as Agbeve herbal Centre products affirmed their willingness and preparedness to consume local products more often because of certain benefits that come along with it. The Agbeve herbal Centre products produced in Ghana because of proximity have several substitutes to choose from. It therefore presents a choice of selection for comparing prices. About $8 \%$ of the sampled respondents attested to this fact while $3 \%$ were of the opinion that locally manufactured products are easily available even though they were quick to add that when it was in short supply it took rather a long time to get new supplies. Additionally, about $15 \%$ held the view that, most products produced in Ghana are of better quality than foreign products. 
Table 4.3.2: Reasons for Purchasing Agbeve herbal Centre products

\begin{tabular}{|l|l|l|}
\hline RESPONSES & FREQUENCY & PERCENTAGE\% \\
\hline Local Products of better quality than foreign ones & 30 & 15.0 \\
\hline Compelled to Buy/ Have No Choice & 62 & 31.0 \\
\hline Relatively Cheaper & 56 & 28.0 \\
\hline Easily Available & 6 & 3.0 \\
\hline Several Alternatives/Substitutes & 16 & 8.0 \\
\hline To Protect Local and Infant Industry & 7 & 3.0 \\
\hline To Retain Profit in the Country & 0 & 0.0 \\
\hline To help Expand market of Local Producers & 24 & 12.0 \\
\hline Total & 201 & 100 \\
\hline
\end{tabular}

Source: Field Data (2018).

\subsection{Impressions of Packaging of Foreign Products}

Having seen such encouraging behavior by more than half of the sampled respondents concerning their willingness to buy Made-in-Ghana products, it was interesting to assess the impressions of the respondents about the packaging of the imported products. Also, there has been a high influx of foreign products in the country recently and they are strenuously competing with the local products. In most cases, they are crowding out the local ones. With the high economics of scale of foreign industries, they are able to relatively cut down the prices of their products thereby affecting the sales of local producers.

Foreign products have been given more prominence in the country than locally produced products. There were positive impressions provided by respondents on account of foreign products. They think their products are well-packaged, it protects the contents very well, and information provided on the product is adequate while also the designs of their packages seem present. Table 4.4 presents the results of this analysis.

Table 4.4: Impressions of Packaging of Foreign Products

\begin{tabular}{|l|l|l|}
\hline Impression & FREQUENCY & PERCENTAGE\% \\
\hline Well Packaged & 46 & 23 \\
\hline Protects the products Very Well & 66 & 33 \\
\hline Provides all the Needed Information & 9 & 4 \\
\hline Good Design of Package & 62 & 31 \\
\hline Beautiful in Terms of Colors and Shape & 18 & 9 \\
\hline Total & 201 & 100 \\
\hline
\end{tabular}

Source: Field Data (2018).

\subsection{Impressions of Packaging of Locally Manufactured Products}

While respondents have given a good impression about the packaging of foreign products; it was also expedient for the study to capture the impressions of respondents on packaging of locally manufactured products. Table 4.5 describes the results of this analysis. As depicted in Table 4.5, there is a high incidence of Agbeve herbal Centre products which are shabbily packaged as about $33 \%$ of the respondents argued. Most local products are poorly done not considering the thorough interest of the consumer. The consumer's welfare is not factored into the production of local products. As a result of the shabby nature of products produced, goods are not attractive. This accounts for $22.8 \%$ of the distribution. Most Made-in-Ghana products and in this case, products produced by Agbeve herbal Centre products lack adequate information on instructions and usage (3.7\%). This habit may have an enormous ramification on consumers with regards to the use of certain products. Lack of cultural elements on the packaging of Ghanaian products was one of the concerns raised by consumers. They believe our products could be restructured the Chinese way thereby using symbolic local text and signs to portray our culture and identity and as well promoting our products.

Table 4.5: Impressions of Packaging of Locally Manufactured Products

\begin{tabular}{|l|l|l|}
\hline RESPONSES & FREQUENCY & PERCENTAGE\% \\
\hline Not attractive & 46 & 22.8 \\
\hline Shabbily done & 66 & 33 \\
\hline Inadequate information provided & 8 & 3.7 \\
\hline Exposed product content & 81 & 40.5 \\
\hline Total & 201 & 100 \\
\hline
\end{tabular}

Source: Field Data (2018). 
delved into ascertaining any instance of Agbeve herbal Centre's products rejection as a result of poor packaging and the results revealed that out of the overall respondents, more than half of the respondents being $65 \%$ had rejected products on account of poor packaging as can be seen from table 4.6.

Table 4.6: Instance of Product Rejection

\begin{tabular}{|l|l|l|}
\hline ITEM & FREQUENCY & PERCENTAGE\% \\
\hline YES & 131 & 65.0 \\
\hline NO & 70 & 35.0 \\
\hline TOTAL & $\mathbf{2 0 1}$ & $\mathbf{1 0 0}$ \\
\hline
\end{tabular}

Source: Field Data (2018).

4.7 Differences between Packaging of Foreign Products and Made-in-Ghana Products

A comparative study was carried out to assess the difference between packaging of foreign products to Made-inGhana products. This was necessary to inform decision making because most consumers have a disregard for local products but however are compelled to buy because of necessity. This is elaborated in the 4.7 below

Table 4.7: Differences between Packaging of Foreign and Made-in-Ghana Products

\begin{tabular}{|l|l|l|}
\hline RESPONSES & FREQUENCY & PERCENTAGE\% \\
\hline Foreign Products are of High Quality & 26 & 12.7 \\
\hline Foreign Products are well packaged than Local ones & 33 & 16.5 \\
\hline $\begin{array}{l}\text { Foreign Products appear more attractive in Terms of Color and } \\
\text { Shape than made in Ghana products than made in Ghana } \\
\text { products }\end{array}$ & 40 & 19.8 \\
\hline $\begin{array}{l}\text { Foreign Products have adequate information on its label than } \\
\text { local products }\end{array}$ & 32 & 16.0 \\
\hline $\begin{array}{l}\text { Foreign Products are made with Quality Materials compared to } \\
\text { made in Ghana products }\end{array}$ & 20 & 10.0 \\
\hline Foreign Products Last Longer than made in Ghana products & 19 & 9.8 \\
\hline $\begin{array}{l}\text { Foreign Products have Good Design than made in Ghana } \\
\text { products }\end{array}$ & 15 & 7.7 \\
\hline Virtually No difference & 16 & 7.5 \\
\hline TOTAL & $\mathbf{2 0 1}$ & $\mathbf{1 0 0}$ \\
\hline
\end{tabular}

Source: Field Data (2018).

According to the opinion of respondents from Table 4.7, 16 respondents representing $7.5 \%$ think there is virtually no difference between both products. On the reverse, there were high scores for foreign products among some of which are products are attractively made (19.8\%). The variable "products are well packaged" accounted for (16.5\%) while "products providing needed information" also accounted for (16\%). More so, respondents think foreign products are of high quality which constitute for $10.0 \%$ while $9.8 \%$ others also think that foreign products last longer.

\subsection{Reaction of Consumers and Sellers}

Reaction is a response that reveals a person's feelings or attitude. Reaction of both parties was considered on account of instances of product rejection from the viewpoint of the consumer. This was done to demonstrate to manufacturers and designers that there are repercussions for any inappropriate designs they made for the packaging of any products. Sometimes, it even led to fights between buyers and sellers. Table 4.8 clearly depicts the various scenarios.

Table 4.8: Reaction of Consumers and Sellers

\begin{tabular}{|l|l|l|}
\hline Reactions & FREQUENCY & PERCENTAGE\% \\
\hline Disappointment & 46 & 23.0 \\
\hline Got Annoyed & 46 & 23.0 \\
\hline Asked for Reasons & 7 & 3.0 \\
\hline Refunded money back & 62 & 31.0 \\
\hline Would not take back the product & 18 & 9.0 \\
\hline Blamed the manufacturers & 22 & 11.0 \\
\hline Total & 201 & 100 \\
\hline
\end{tabular}

Source: Field Data (2018)

\subsection{Problems Associated with Products}

From Table 4.8, complaints are first raised by identifying the reasons for the problems associated with the product. This is the major reaction expressed by consumers accounting for 3\%. Manufacturers of such substandard product 
would be blamed and afterwards consumers would become disappointed. On the other hand, reaction of sellers according to the majority of respondents are to ask for reasons and subsequently manufacturers would be blamed and as such they would be disappointed. These three major reactions identified by seller's runs concurrently with the three major reactions of consumers. Consumer's displeasure on Agbeve herbal Centre products rejection is highly attributed to expired products by blaming manufacturers $(11 \%)$. Packaging of some products easily gets faded thereby making reading of instruction and other vital information difficult. The rest of the distribution is depicted Table 4.9.

Table 4.9: Problems Associated with Products

\begin{tabular}{|l|l|l|}
\hline Reactions & FREQUENCY & PERCENTAGE\% \\
\hline Product had expired & 46 & 22.8 \\
\hline No expiry date & 66 & 33 \\
\hline No information on usage & 8 & 3.7 \\
\hline Package was faded & 81 & 40.5 \\
\hline Total & 201 & 100 \\
\hline
\end{tabular}

Source: Field Data (2018).

\subsection{Cultural Elements Required for Promoting Made-In-Ghana Products}

In a bid to blending the style and design of packaging to enhance its shape and beauty as well as quality, an aspect of information elicited was to know from the consumers the cultural elements that can promote Made-in-Ghana products, Table 4.10 depicts the circumstances. Respondents required the use of symbols in the design of products for packaging. Symbols of traditional heritage like "Adinkra Symbols" could be adopted. This can also broaden the horizon of users because of its special meanings. Those who opted for symbols to be used accounted for $34.9 \%$ while the highest majority being 81 respondents constituting $40.1 \%$ wanted the use of colours which may reflect Ghanaian identity. Again, a section of respondents wanted the use of pictures of great heroes of the country. They represent $6.7 \%$ of the distribution. The use of local language for the literature on the packaging was also highlighted accounting for $18.3 \%$.

Table 4.10 Cultural Elements Required for Promoting Made-In-Ghana Products

\begin{tabular}{|l|l|l|}
\hline RESPONSES & FREQUENCY & PERCENTAGE\% \\
\hline Symbols & 70 & 34.9 \\
\hline Colors & 81 & 40.1 \\
\hline Local Language & 37 & 18.3 \\
\hline Pictures of National Heroes and Others & 13 & 6.7 \\
\hline Total & 201 & 100 \\
\hline
\end{tabular}

Source: Field Data (2018).

\subsection{Suggestions on Improving Made-In-Ghana Products}

With poor packaging of Made-in-Ghana products as acknowledged by respondents which is in significant contrast to that of the foreign ones, the study sought to find out how packaging of Ghanaian products could be improved and these suggestions are first the incorporation of Ghanaian symbols like the "Gye Nyame" and colours to give Ghanaian products an identity. Second, the contact addresses and locations of manufacturers should be well outlined on the package. Third is the provision of all needed and necessary information on instruction and usage. Also there is a high need for modification of product designs in terms of shapes and sizes factoring an interesting blend of colour to attract consumers. Furthermore, quality and right packaging material should be used to protect product to make it last till its expiry date. Lastly, reposition of manufacturing and expiry dates by making it easily placed so that consumers can easily check at a glance is essential.

\subsection{Challenges facing the Local Packaging Industry (structure-wise)}

One of the objectives of this study was to provide factual evidence about the impact that any observable change in the packaging of a product would have on the sales trend and ultimately the profit margins of the manufacturer. Since the focus is on encouraging local manufacturers to take key interest in the packaging of their products, a purely locally manufactured product was selected. This section provides in detail the outcome of the quest to answer the above objective. This section concludes by establishing the truism in the thinking that, an improvement in packaging results in increase in sales trend.

4.12.1. The capital intensive nature of the industry

The capital intensive nature of the industry which demands modern, automated equipment for large scale production is a big challenge to the industry. This has hampered the growth of the industry because many small scale enterprises cannot afford this equipment. 


\subsubsection{The absence of a Ghanaian glass manufacturing company}

The absence of a Ghanaian glass manufacturing company such as the now defunct Aboso Glass Factory is also a challenge to the industry since all glass packages in the country are either imported from Nigeria or South Africa. 4.12.3. Increased demand in packaging

The local packaging industry is further challenged by the increased demand in packaging owing to such factors as the trend towards smaller households, the increasing requirements for convenience among consumers and the rising health awareness among consumers.

\subsubsection{High Quality Packages demanded}

The exposure of the Ghanaian middle-class to high quality packaging has shifted the demand towards wellpackaged, clearly labelled and environmentally friendly products. This has also been a challenge to the industry because it is expected to meet these needs of the middle-class.

\subsubsection{Trade liberalization}

It was also noted that the liberalization of trade in Ghana has led to foreign manufacturers of packaging entering the local market and producing relatively more attractive packaging at affordable prices. This has led to the increased patronage of packages from these new entrants while packaging produced by local manufacturers has not seen similar growth.

\subsubsection{Increasing awareness of environmental issues}

The fact that consumers have increasingly been made aware of the effect packaging has on the environment has also become a challenge to the industry since they have to find means of producing packages that would reduce the negative effects of packaging on the environment as much as possible.

\subsubsection{New packaging material development}

Imported products come in a variety of materials used for the packaging. Materials such as glass (in interesting shapes and colour), fabric, wood, and special cards are being used to package imported products, throwing a big challenge to the local industry.

\subsubsection{Growing requirements for brand enhancement}

Education and the sight of imported products have enlightened many consumers about what a good packaging structure is. As a result, there is a growing urge for brands to be enhanced by manufacturers. This is a challenge to local manufacturers, many of whom do not have the means to meet such expectations.

\subsubsection{Lack of expertise in packaging design}

The lack of packaging design experts has hampered packaging development. There are very few packaging design experts compared to the number of SMEs in the country. Ghana, to a large extent, lacks packaging design experts to help in such areas as design, and production of packaging structures. As a result, there are many manufacturers who are ready to improve upon their packages but cannot get the necessary expertise.

\subsubsection{Poor Finishes}

This is an area where the manufacturers lacked the expertise and technical abilities, thus leading to poorly-finished packages. It is therefore very important that more care be taken in packing and handling of products as regards their packaging so as to ensure proper sealing and packing to maintain the integrity of their packages and thus increase the patronage for their products. This is because a very good package makes the product more believable and may even cause consumers to buy the products on impulse.

\section{Conclusion}

Products are not purchased only for the sake of the product as good packaging plays a vital role in the purchasing intention of customers when it comes to a product. It is therefore very necessary that local manufacturers attach a high level of interest in their packaging to increase sales both locally and internationally. The focus of this study was to identify the benefits of packaging in the right way which would also reflect Ghanaian culture and establish its relationship with sales trend and make implementable recommendations aimed at improving the packaging industry in Ghana using Agbeve herbal products as a case study. This research was carried out by using Agbeve herbal products as a case study and comes at a time that the local manufacturers are struggling with dwindling sales while the consumer is always complaining about the deteriorating nature of the packaging of the locally manufactured products. Various state institutions such as FDB and the GSB as well as private organizations such as AGI, PEF and IOPG are also trying frantically to deal with the above issues. Hence, the relevance of this study cannot be over emphasized. The analysis of the consumers confirmed that to a very large extent purchasing decisions are mostly made at the point of sale and that the aesthetic value and the adequacy of information provided on the label of the product are key influencing factors in choosing which product to purchase. Sellers/retailers also confirmed this assertion and stressed that the packaging (structure and label) of most Made-in-Ghana products do not portray these qualities. Consumers also believe that the use of cultural elements in the packaging of local products could influence their decision to purchase those products. Manufacturers on the other hand need to accept that some level of cost is associated with ensuring that the packaging of their products contains what would attract the consumer. The institutions that were investigated all showed some level of inadequate capacity. Poor or 
improper labelling of packaged products for the local market can be blamed largely on inadequate enforcement of labelling regulations by the mandated organizations. Both packaged product manufacturers and packaging graphic designers can also be blamed partly because of their poor interest in using the labelling rules and standards documents as reference material in their works. Intensive consumer researches are not carried out by majority of local manufacturers to gain the necessary customer inputs for their product packaging design. The consumer research approaches used by most of them are not effective as they undertake the task too casually. This condition can cause their respondents to take the exercise less serious. This makes it difficult for them to detect errors and customers $^{\text {ee }}$ reactions to their packaging concepts at the early stage of their packaging development. It also makes it difficult for them to satisfy their customers with better packaging that meets quality requirements.

The study recommends that recycling of a package or its component for other purposes should be encouraged by managements of organizations. Also, budgetary allocation for packaging by management should be increased to ensure quality work is done. In developing a package, management should take into consideration the protection of the environment and its habitats so as to use environmentally friendly materials. Organization must be encouraged to set up a whole department meant for designing packaging so as to inculcate some professionalism touch into their final work.

\section{References}

Ampuero, O., \& Vila, N., 2006. Consumer perceptions of product packaging. Journal of Consumer Marketing, 23(2), 100-112.

Andualem, T., \& Gebre-Mariam, T. (2004). Assessment of Consumers Drug Knowledge in Addis Ababa: A CrossSectional Survey. Ethiopian Journal of Health Sciences, 14(2).

Assenso-Okyere W, Anum I, Osei A kkoto J andAdonkonu (1998): Cost recovery in Ghana; are there any changes in health seeking behavior? Health policy planning, p13

Bloch, P.H., 1995. Seeking the ideal form: product design and consumer response. Journal of Marketing, 59 (July), 16-29.

Butkeviciene, V., Stravinskiene, J., \& Rutelione, A., 2008. 'Impact of consumer package communication on consumer decision making process', Inzinerine Ekonomika-Engineering Economics (1), pp. 57-65.

Cocks, M. L., \& Dold, A. P. (2006). Cultural significance of biodiversity: the role of medicinal plants in urban African cultural practices in the Eastern Cape, South Africa. Journal of Ethnobiology, 26(1), 60-81.

Coles, R., \& Kirwan, M. J. (2011). Food and beverage packaging technology. John Wiley \& Sons.

Darko, S., Terkper, V. D., Novixoxo, J. D., \& Anning, L. (2018). Assessing the Effect of Lead Time Management on Customer Satisfaction.

Dauvergne, P., \& Lister, J. (2012). Big brand sustainability: Governance prospects and environmental limits. Global Environmental Change, 22(1), 36-45.

Dieringer, N. J., Kukkamma, L., Somes, G. W., \& Shorr, R. I. (2011). Self-reported responsiveness to direct-toconsumer drug advertising and medication use: results of a national survey. BMC health services research, 11(1), 232.

Donohue, J. M., \& Berndt, E. R. (2004). Effects of direct-to-consumer advertising on medication choice: The case of antidepressants. Journal of Public Policy and Marketing, 23(2), 115-127.

Faus, N. L., \& Pierce, D. L. (2016). U.S. Patent No. 9,323,519. Washington, DC: U.S. Patent and Trademark Office.

Finck Barboza, C., Monteiro, S. M., Barradas, S. C., Sarmiento, O. L., Rios, P., Ramirez, A., ... \& Pratt, M. (2013). Physical activity, nutrition and behavior change in Latin America: a systematic review. Global health promotion, 20(4 suppl), 65-81.

GIA, 2011. Global Industry Analysts, Inc. Report

Hebert, R. C., Huffer, S. W., Reese, B. R., \& Prizzi, J. A. (2010). U.S. Patent No. 7,717,620. Washington, DC: U.S. Patent and Trademark Office.

Holmes, G. R., \& Paswan, A. (2012). Consumer Reaction to New Package Design. Journal of Product and Brand Management, 109-116.

Ilić, Z. S., Trajković, R., Pavlović, R., Alkalai - Tuvia, S., Perzelan, Y., \& Fallik, E. (2012). Effect of heat treatment and individual shrink packaging on quality and nutritional value of bell pepper stored at suboptimal temperature. International journal of food science \& technology, 47(1), 83-90.

Konnikova, M. (2014, December 17). How Headlines Change The Way We Think. Retrieved May 26, 2015, from The New Yorker: http://www.newyorker.com/science/maria-konnikova/headlines-change-way-think

Kruparova, P. (2007). U.S. Patent Application No. 29/266,452.

Lu, D., \& Weng, Q. (2007). A survey of image classification methods and techniques for improving classification performance. International journal of Remote sensing, 28(5), 823-870.

Madden, T. J., Hewett, K., \& Roth, M. S., 2000. Managing images in different cultures: A cross-national study of color meanings and preferences. Journal of International Marketing, 8(4), 90-107. 
McDonough, R. P. (2013). Embodying the principles of clinical pharmacy. Pharmacy Today, 19(12), 56.

Moran, J. R., \& Simon, K. I. (2006). Income and the Use of Prescription Drugs by the Elderly Evidence from the Notch Cohorts. Journal of Human Resources, 41(2), 411-432.

Nonvignon, J. M KS Aikins, M.K.S, Chimbuah, M.A, Gyapong, M. A.M, Garshong, B. N.A. Savior Fia, and Gyapong J.O(2010) "treatment choice for fever in children under -five years in rural Ghanaians districts" Malaria journal.

Novixoxo, J. D., Abubakar Jamal-Deen, L. A., \& Darko, S. (2018). The Effect of Branding On the Marketing Performance of Companies in the Mobile Phone Industry (Case Study of Techno Ghana, Accra).

Novixoxo, J. D., Wongnaah, F., Anning, L., \& Darko, S. (2018). The Influence of Price on Customer Loyalty in the Retail Industry Scholars Bulletin (Marketing).

Okano, M., Bell, D. W., Haber, D. A., \& Li, E. (1999). DNA methyltransferases Dnmt3a and Dnmt3b are essential for de novo methylation and mammalian development. Cell, 99(3), 247-257.

Panwar, J. S. (2004). Beyond consumer marketing: sectoral marketing and emerging trends. SAGE Publications India.

PIRA International (2009). Commercial exploitation of Europe's Public Sector Information, Final Report, Prepared for the European Commission, Surrey: Pira International.

Risgalla, E. (2006). U.S. Patent Application No. 29/203,443.

Robertson, D. W. (1965). U.S. Patent No. 3,195,770. Washington, DC: U.S. Patent and Trademark Office.

Rocchi, B., \& Stefani, G. (2006). Consumers' perception of wine packaging: a case study. International Journal of Wine Marketing, 18(1), 33-44.

Sevilla, J. (2012). When It's What's Outside That Matters: Recent Findings on Product and Packaging Design. ACR North American Advances.

Sevilla, J. (2012). When It's What's Outside That Matters: Recent Findings on Product and Packaging Design. Advances in Consumer Research, 308-312.

Soroka, W. (2002). Fundamentals of Packaging Technology, Institute of Packaging Professionals, St. Charles, IL.

Spokane Falls Community College. (2013, May 3). Spokane Falls Community College. Retrieved May 25, 2015, from Spokane Falls Community website: http://graphicdesign.spokanefalls.edu/tutorials/process/gestaltprinciples/gestaltprin c.htm

Statistical Abstract of the United States 2009 (Hardcover). Government Printing Office, 2008.

Suppakul, P., Sonneveld, K., Bigger, S. W., \& Miltz, J. (2011). Diffusion of linalool and methylchavicol from polyethylene-based antimicrobial packaging films. LWT-Food Science and Technology, 44(9), 1888-1893.

Underwood, R.L., Klein, N.M., \& Burke, R.R., 2001. Packaging communication: attentional effects of product imagery. Journal of Product \& Brand Management, 10 (7), 403-422.

Wake, W. K. (1989). U.S. Patent No. 4,796,201. Washington, DC: U.S. Patent and Trademark Office.

World Health Organization, \& WHO Tobacco Free Initiative. (2009). World No Tobacco Day 2009: showing the truth, saving lives: pictorial health warnings on tobacco packaging.

Yamane, T. (1967). Elementary sampling theory. 